\title{
ТЕРАПИЯ ОСОЗНАННОСТЬЮ, КАК МЕТОД РАЗРЕШЕНИЯ ВНУТРИЛИЧНОСТНЫХ КОНФЛИКТОВ
}

Хулапов А.А., Тесля С.Н.

О внутриличностных конфликтах в психологии известно уже более ста лет и, казалось бы, психотерапия многого достигла в плане управления или преодоления внутриличностной конфликтности, однако этот феномен так и остается теоретической и практической проблемой для современной практикоориентированной психологии. В этой связи, представим некоторые соображения, возникшие в процессе знакомства с трудами разных лет В.Н.Дружинина, в частности, с его работой «Творчество: природа и развитие», с той ее частью, что обозначена как «Формирование креативности и обучаемость» [1]. Суть этих соображений можно выразить в сложной гипотезе. На наш взгляд:

1.Внутриличностный конфликт, проведенный через терапию осознанностью, может стать действенным фактором развития креативности субъекта до творческого стремления, и, в случае, если субъект «научится управлять» некоторыми акцентуациями своей личности, он уже не будет переживать вновь рецидивы внутриличностных противоречий и обрекать себя на «анализы» и консультирование, где его будут учить временно «снимать» напряженность. Но, в целом, он будет оставаться в плену того типа критической ситуации, которая (согласно классификации Ф.Е. Василюка) называется «инфантильным жизненным миром»[2].

2.Благодаря эффекту осознанности, которая невозможна без такой культур-антропологической константы человека как сознание, субъект будет способен и готов (на уровне смысловой установки) идти дальше - по пути творчества, реализуя не только насущные потребности, но и человеческое предназначение - быть субъектом жизни.

3. Мы вправе предположить, что сама по себе терапия не имеет смысла, если только она не служит «дверью» к более широкому контексту жизни, нежели «частная, личная», жизнь автономного индивидуума, привыкшего жить по правилам. Следовательно, когда речь идет о внутриличностном конфликте и, особенно, об определенных акцентуациях личности, можно утверждать их продуктивность в плане пред-понимания субъектом себя именно как творческого человека.

4. Естественно, в этом контексте, на одно из первых мест выдвигается проблема профессионального позиционирования терапевта, его задачи как терапевта-посредника, терапевта-медиатора - между реально-зациклившимся на акцентуации индивидуумом и его духовным ростом к себе-творческому.

Важным для нас оказалось одно замечание В.Н. Дружинина: «Среда, в которой креативность могла бы актуализироваться - пишет он -, обладает высокой степенью неопределенности и потенциальной многовариантностью $[1, \mathrm{c.95}]$. В дальнейшем, описывая формирующий эксперимент, целью которого было выяснить, влияет ли такая среда на креативность поведения, Дружинин (работая с детьми, с которыми регулярно взаимодействовали взрослые, то есть, 
были в контакте), естественно, обращается к игре, в которой креативная ценность игрового действия определялась отнесением каждого придуманного события к нескольким типам. Нас привлек первый указанный им тип игрового события, а именно:

«1. Событие понимается как постановка проблемы, предполагающей множественность решений, дающей толчок дальнейшему развитию игры [1, с.95]». На наш взгляд, именно с этим типом «придуманного события» «играет» субъект с выраженным внутриличностным конфликтом.

Углубляясь в описания внутриличностного конфликта, можно провести такую аналогию: то, что В.Н. Дружинин пишет о «среде, в которой могла бы актуализироваться креативность», можно отнести к самому внутриличностному конфликту, рассматривая его как ту «субъективную среду», в которой может актуализироваться творческий потенциал субъекта.

В эксперименте Дружинин замерял уровни креативности испытуемых и было выявлено, что «преобладающей является следующая тенденция: вслед за существенным повышением наблюдается ее некоторое понижение» [1, с.97] и тут же, он делает ключевое для нашей темы предположение: «Может быть, объяснение следует искать не в средовом влиянии, а в изменении личностных структур испытуемых... Вероятно, процесс преобразований затрагивает не только креативные свойства, но и некоторые другие (личностные) образования, динамика изменения которых может отражаться на динамике изменения креативности» [1, с.99]. И далее В.Н.Дружинин указывает на особенности второй половины эксперимента, о которых мы пока умолчим, но отметим, что именно эта информация заставила нас внимательнее присмотреться к акцентуациям, которые сопровождают внутриличностный конфликт. И, одновременно, воспринять формирующий эксперимент В.Н. Дружинина как модель терапии осознанностью, во многом схожую $c$ гештальт-терапией. Но - по порядку. Кратко о понятии «внутриличностный конфликт».

Слово «конфликт» восходит к латинскому значению «conflictus», что значит «столкнувшийся». «Столкновение» это, очевидно, наиболее острый момент контакта. Понятие «контакт» - одно из ключевых. Мы опираемся на схему контакта, хорошо известную в гештальт-терапии: преконтакт, контактинг, финальный контакт, постконтакт [3].

Если перенести значение «столкнувшийся» на «внутриличностный конфликт», то можно сказать, что это - «столкновение» чего-то с чем-то, находящимся в тесном контакте именно «внутри» личности. Что же с чем сталкивается, переживаясь личностью болезненно? - Ясно, что речь идет об остром столкновении разнонаправленных, противоречащих друг другу, желаний, потребностей, мыслей. И, как следствие, - парализация их поведенческих коррелятов - и на уровне актов, и на уровне действий, и на уровне поступков.

Почему же это происходит? Возможный ответ: «потому, что у него есть и то, и другое, и третье, но нет «всего»! А «все» имеет очень высокий ценз неопределенности! В итоге, сама рационально привитая в ходе социализации 
последовательность удовлетворения и реализации желаемого и мыслимого фрустрирует самого «носителя» желаний, потребностей и мыслей самого индивидуума. И уже ясно: причины следует в пространстве переживаний, в чувственно-эмоциональной сфере.

Отметим, что, когда речь идет именно о внутриличностном конфликте, ему сопутствуют экзистенциальные переживания: тревога, беспокойство, маета, бессонница, агрессия, озлобленность (Resentiment). И вот, для сравнения, данные «детского» эксперимента ВНД: «Особенностями второй половины эксперимента являются повышенная конфликтность (агрессивность), неустойчивость настроения, высокая амплитуда колебаний эмоционального состояния, подверженность отрицательным эмоциям, тревожность, сензитивность, перевозбуждение.... Можно отметить выраженные изменения в эмоциональной сфере испытуемых. Характер изменений в эмоциональной сфере можно условно определить как невротический... - пишет Дружинин [1, c.99.]. Понимая, что невротик это универсальная характеристика социального субъекта, особенно с точки зрения психоанализа, мы в своем исследовании дифференцировали это понятие с помощью трех акцентуаций. Это: шизоидная (1), собственно, «невротическая» или пограничная (2) и нарциссическая (3) акцентуации.

Направляясь в сторону мира переживаний, находим уже хорошо описанные причины, влекущие за собой, внутриличностный конфликт: это и стресс, и психологические травмы, и интроекты, и другие причины, варьирующие в зависимости от той концепции, которой придерживается ученый, изучающий механизмы внутриличностных конфликтов. Описан и сам внутриличностный конфликт. Детальная его модель представлена, например, в динамической концепции личности Д.Н. Хломова [4], базирующейся на теории гештальт-терапии П. Гудмана и Ф. Перлза [5].

Согласно этой концепции, индивидуум имеет как физиологические, так и психологические гранищы, посредством которых он определяет для себя оптимальные диапазоны контакта с социальной средой, в которой видит источник реализации своих потребностей. Контакт со средой может быть успешным, а может прерываться на различных стадиях, и это прерывание связано с определенными акцентуированными чертами личности, которые образовались в результате патогенных, травматических процессов, происходящих в различные периоды жизни, особенно в детстве, и представляют собой, - считает Хломов - прерванные и нереализованные потребности в безопасности, слиянии и манипулировании. Этим нереализованным потребностям и способам построения и завершения контакта из многочисленных акцентуаций, выведенных в рамках неопсихоанализа, как раз, и соответствуют шизоидная, невротическая и нарциссическая акцентуации личности (или «типы личности» по С. Шону). Они оказывают негативное действие на развитие контакта, а именно: «шизоидный уход», «невротическое залипание», «нарциссическое обесценивание» [6].

Естественно, данные акцентуации личности представляют собой защитные механизмы психики, являющиеся актуальными в момент определенной угрозы 
для нее на ранних стадиях развития личности, но в настоящий момент являющиеся архаичными механизмами, прерывающими контакт - в виде аффективной реакции, не оставляющей человеку выбора и возможности его совершать и утверждать в действии.

Интересно, что, практически, в этом же ключе размышляет и В.Н.Дружинин, продвигая и нашу мысль дальше. Он пишет: «Многие выявленные во второй части эксперимента способы эмоционального реагирования детей (плач, агрессия) являются, видимо, различными архаичными вариантами психологической защиты от дальнейшего развития креативных свойств. Наравне с формированием установки на проблемность мышления... набирает силу отвержение такой установки как вредной, препятствующей определенному способу функционирования (высокий уровень креативности отвергается системой жизнедеятельности индивидуума)» [1, c.99 -100].

Таким образом, креативность оказывается вредной для системы жизнедеятельности индивидуума, и он хочет вернуться к привычным стереотипам поведения, восстановить равновесие. И этот эффект не стоит сбрасывать со счетов, тем более, что он «работает» на улучшение психоэмоционального состояния индивидуума, и еще К. Левин предупреждал, что не всякий клиент готов «вынести» высоту, на которую может поднять его психолог-терапевт, и следует быть чутким к запросу клиента.

Задачей терапии, в этом контексте, является: обнаружив, скажем, невротическую акцентуацию, прожить травму, и открыть возможность индивидууму сделать выбор, который восстановит равновесие, вернет в спокойное состояние, когда субъекту станет ясно, что он может реализовывать контакт - и не только с терапевтом, но и со средой, миметическим образом которой является терапевт.

Процесс психотерапии проходит, параллельно используя два метода: личную и групповую терапию, в результате которых человек учится осознавать и осознавать себя определившимся. В гештальт-терапии под осознанием понимается не только понимание происходящих процессов и потребностей, но и проживание приходящих с ними чувств. Это проживание не есть что-то само собой разумеющееся, но, по сути, есть сам живой опыт, onыл как цуенность жизни. И эта иченность жизни моделируется в контакте с терапевтом.

В начале терапии человек учится описывать свои потребности, вербализуя, понимать их, видеть свои аффективные защитные механизмы, проживать базовые потребности и травмы, приобретая посредством группы и терапевта варианты возможных действий, освобождаясь от жестких оков обусловленных жизненных сценариев и обретая тем самым свободу выбора.

В процессе терапии терапевт является соучастником и проводником процесса клиента. Отличием терапевта от клиента является глубина осознанности и вариативность выборов (повышенная чувствительность терапевта). В терапии терапевт присутствует своей осознанностью, вниманием, эмпатией и, в зависимости от того, как развивается процесс клиента, терапевт либо фрустрирует, либо поддерживает происходящий процесс (терапевт лечит 
своими травмами - в этом смысл «пройти свой психоанализ», «свою гештальттерапию»). Он помогает клиенту либо удержать процесс, фигуру потребности, либо прервать или корректировать разворачивание фигуры, если у клиента недостаточно ресурса для проживания травматического опыта, или данная фигура перекрывает другую, основанную на более базовой потребности.

Здесь стоит немного подробнее остановиться на вышеописанных акцентуациях. Все они присутствуют в личности человека, различаются только по степени выраженности, а также по характеру акцентуации (н-p, она может быть «адаптивной», а может - «деструктивной»). И здесь важно подчеркнуть, что эти характерологические черты акцентуаций являются проявлением аналогичных функций Self или «самости». Так, шизоидная акцентуация характеризуется такими качествами личности, как уход в себя, аутичность, раздробленность, фрагментарность. Шизоидыне умеют формировать привязанность, боятся развивать контакт из-за страха поглощения и уничтожения. Ведущей эмоцией в прерывании контакта является ужас. Психологические защиты, используемые шизоидной акцентуацией, это «дефлексия» и «проекция».

Для невротической (пограничной) акцентуации личности характерны беспомощность, невозможность пребывать без других. Невротикам тяжело быть индивидуальными, отделяться от других, они стараются, идти на слияние с другими. Ведущей пугающей эмоцией является страх отвержения, одиночества, покинутости. Психологические защиты - интроекция и конфлюэнция.

Нарциссическая акцентуация личности характеризуется сменяемой полюсностью величия и ничтожности. Нарциссы замкнуты на своем внутреннем конфликте, им сложно сочувствовать и сопереживать другим людям. Испытывают страх оказаться неценным, униженным, встретиться с фактом неважности его жизни, действий и достижений с точки зрения других людей, пугает чувство стыда. Психологические защиты - дефлексия, проекция, эготизм.

По сути, вышеперечисленные акцентуации являются примером пассивной адаптации Self, а вариант свободного формирования и реализации потребности - пример продуктивного приспособления Self, в основе которого лежит осознанность. В связи с этим тезисом, Шизоидная, Невротическая и Нарциссическая акцентуации личности - это классификация эмоциональноаффективных нарушений, проявляющихся в контакте, заставляющих индивидуума сопротивляться контакту.

Отсюда - задачи психотерапевта: следовать установкам, связанным с достижением осознанности через проживание переживания, которому клиент сопротивляется. Смысл установки - снять сопротивление. Метод - поддержка сопереживанием. Эффект происходит благодаря размылканию границы, создаваемой акцентуацией. Установка терапевта на контакт-отношение создает эффект поля, более широкого, нежели поле клиента.

Таким образом, осознанность оказывается терапевтическим фактором, потому что снимает сопротивление своим само-ограничениям. В ходе терапии, 
терапевт производит такое отношение к клиенту, попадая в поле которого клиент идет на свой страх и риск туда, куда ему идти самому не хватало сил, да и в голову не приходило, поскольку сопротивление шло на бессознательном уровне.

Ключевым понятием для понимания смысла осознанности становится понятие «поле», как его понимал К. Левин, коннотирующее не с «границей», но c «горизонтом», «расширением», «размыканием». Но, главное, осознанность, как полевой феномен, не принадлежит автономному индивидууму, но по природе своей контекстуально.

Выводы. По сути, следствием такой терапии является рождение социально адаптивной, осознающей свои потребности индивидуальности. А что же дальше? Концепция идеального и опытного эгоиста явно ограничена, хотя четко идентифицирующийся в социуме субъект ему (социуму) просто необходим. Тут - такое предположение:

Поскольку все акцентуации связаны c Self, a, следовательно, жестко завязаны на Другого, то, в силу этого, креативность, которую проявляют клиенты в ходе терапии - не та, о которой говорим мы, поскольку мы делаем акцент на творческом потенциале субъекта, который, как раз, и не обусловлен Другим. Поэтому: если посмотреть на это как на естественный и необходимый процесс роста человека, однако на следующий уровень поставить духовность, то тут и будет гармония. Терапия осознанностью, безусловно, помогает реализовать или научиться максимально эффективно реализовывать свои базовые потребности, но прохождение ее дает возможность подойти и к высшей потребности - в самоактуализации (по А. Маслоу), духовности, творчества, а уже дальнейший способ ее развития каждый ищет для себя сам.

Итак, терапия о которой мы говорим, может быть названа «Контактная терапия осознанностью». Важность контакта: человек получает обратную связь в виде своего собственного onblma. Контакт оказывается ситуативно обусловленной формой отношения именно в силу этой обратной связи. В этом заключается важность и смысл контакта. Структура контакта поэтому должна быть представлена и построена в ходе терапии именно потому, что контакт должен совершиться прохождением последовательно всех его стадий и только в этом случае он завершается опытом, выводящим за границы «базовых потребностей» - к творчеству. Здесь - пределы гештальт-терапии: обрести селф, чтобы он нее отказаться, так как творчество не терпит эго-центрации.

Таким образом, выстраивается оптимистическая связка: «сознание бытие-осознанность - творчество».

\section{Литература}

1. Дружинин В.Н. Творчество: природа и развитие // Психология. Журнал Высшей школы экономики. - 2005. - № 3. Том 2. - С.91-107.

2. Василюк Ф. Е. Психология переживания (анализ преодоления критических ситуаций). — М.: Изд-во Моск. ун-та, 1984.

3. Лебедева Н.М., Иванова Е.А. Путешествие в гештальт: теория и практика. - СПб, М.: Речь, 2015. 
4. Хломов Д.Н. Динамический цикл контакта в гештальт-терапии/ Гештальт-2003 // Сборник материалов Московского Гештальт Института / Под ред. Д. Н. Хломова. - М., - Изд-во МГИ. 2003. . - 110 с.

5. Перлз Ф., Гудман П. Теория гештальттерапии. - $\quad$ М.: $\quad$ Институт Общегуманитарных исследований, 2001. - 384 с.

6. Александрова Э.Э. Шизоидный, нарциссический и невротический способы построения и завершения контакта http://users.livejournal.com/esina/566118.html

\section{СВЯЗЬ СТИЛЯ УПРАВЛЕНИЯ С ТВОРЧЕСКИМ ПОТЕНЦИАЛОМ ЛИЧНОСТИ РУКОВОДИТЕЛЯ Шуванов И.Б., Шаповалов В.И., Шуванова В.П.}

В современных условиях важнейшим ресурсом организаций являются управленцы способные быстро реагировать на изменения внешней среды, предлагать нестандартные решения, генерировать оригинальные идеи, разрабатывать инновационные стратегии [4].

Качественные преобразования требуют от руководителей применения эффективных стилей работы с подчиненными. Для упорядочения процесса выбора стиля руководства следует учитывать факторы, которые влияют на их выбор.

Попытки определения стиля руководства в зависимости от различных факторов осуществлялись неоднократно многими исследователями (М.Х. Мескон, Г. Минцберг, Т. Санталайнен, В.П. Симонов и др.).

Подходы исследователей к проблеме динамики стиля руководства, несомненно, обладают цельностью, но вместе с тем имеют и ряд недостатков. Во-первых, каждый из них, как правило, базируется на учете только одного или двух факторов, влияющих на стиль руководства, тогда как практика работы руководителей свидетельствует о том, что на поведение руководителей влияет множество факторов. Во-вторых, следует отметить, что указанные стили руководства рассматриваются как постоянные при определенных стабильных внутренних и внешних условиях. Здесь руководитель проявляет свои естественные, природные свойства характера. Вместе с тем, любой руководитель, кроме основного, может использовать одну или несколько вспомогательных моделей руководства при резком изменении ситуации. Обычно вспомогательная модель применяется чаще тогда, когда основной тип модели «не срабатывает», то есть он не эффективен.

Кроме того, отсутствует четкое представление о личностном содержании стиля деятельности руководителя, что так же делает изучение данной проблемы весьма ограниченным. Ряд авторов в разное время и в достаточно разных контекстах пытались вычленить специфическое содержание и зависимость стиля деятельности от личностных особенностей. Однако это не позволяет говорить о завершенности решения данной проблемы, особенно в части связи стиля деятельности и личностных особенностей, а конкретнее с творческим 